\title{
Current role of endovascular therapy in Marfan patients with previous aortic surgery
}

\author{
Ibrahim Akin \\ Stephan Kische \\ Tim C Rehders \\ Tushar Chatterjee \\ Henrik Schneider \\ Thomas Körber \\ Christoph A Nienaber \\ Hüseyin Ince \\ Department of Medicine, Division \\ of Cardiology at the University \\ Hospital Rostock, Rostock School \\ of Medicine, Ernst-Heydemann-Str. 6, \\ I 8057 Rostock, Germany
}

\begin{abstract}
The Marfan syndrome is a heritable disorder of the connective tissue which affects the cardiovascular, ocular, and skeletal system. The cardiovascular manifestation with aortic root dilatation, aortic valve regurgitation, and aortic dissection has a prevalence of $60 \%$ to $90 \%$ and determines the premature death of these patients. Thirty-four percent of the patients with Marfan syndrome will have serious cardiovascular complications requiring surgery in the first 10 years after diagnosis. Before aortic surgery became available, the majority of the patients died by the age of 32 years. Introduction in the aortic surgery techniques caused an increase of the 10 year survival rate up to $97 \%$. The purpose of this article is to give an overview about the feasibility and outcome of stent-graft placement in the descending thoracic aorta in Marfan patients with previous aortic surgery.
\end{abstract}

Keywords: Marfan syndrome, aortic dissection, root replacement, stent-graft, previous aortic surgery

\section{Marfan disease}

Marfan syndrome is a heritable disorder of the connective tissue with an autosomaldominant transmission and pleiotropic manifestations involving the ophthalmologic, musculoskeletal and cardiovascular systems (Pyeritz and McKusick 1979; Fattori et al 1999). It is a relatively frequent manifestation of the most common genetic disorders, estimated to affect 1 in 6,000 to 10,000 people. The exact prevalence is unknown, but 1 patient who satisfies strict diagnostic criteria is found per 10,000 patients, with no known gender or ethnic predilection.

Both medical and surgical concepts play an integrated role in the therapeutic management of cardiovascular manifestations of the Marfan syndrome and related disorders. Because of cardiovascular involvement, especially aortic dilation with subsequent dissection or rupture, Marfan syndrome is associated with significant morbidity and mortality. The first line therapeutic option for aortic pathologies in Marfan patients is the surgical reconstruction. Because Marfan syndrome is a disease of the entire aorta, there needs a close follow-up.

This article focuses on the cardiovascular aspects of Marfan syndrome and discusses the recent data on the field of endovascular stent-graft placement in Marfan patients with previous aortic surgery.

\section{Cardiovascular manifestations}

The average life expectancy of untreated patients with Marfan syndrome is 32 years (Murdoch et al 1972). In $>90 \%$ of cases in which a cause of death was identifiable, the cardiovascular system was involved, and the most common cause of death was aortic dissection or aortic rupture (Murdoch et al 1972). The cardiovascular manifestations, first described in 1943, are clinically apparent in $40 \%$ to $60 \%$ of patients with Marfan syndrome. Moreover 34\% of patients with Marfan syndrome will have 
serious cardiovascular complications requiring major cardiac surgery in the first 10 years after diagnosis (Groenik et al 1999). A common factor of all phenotypic forms of aortic wall disease is the dedifferentiation of vascular smooth muscle cells not only with classic aneurysm formation, but also from enhanced elastolysis of aortic wall components. In addition, mitral valve prolapse is the most prevalent valvular abnormality, affecting $35 \%$ to $100 \%$ of patients (Van Karnebeek et al 2001). Less commonly reported abnormalities are tricuspid valve prolapse and dilatation of the main pulmonary artery. Thus, for approximately 2 decades, it has become clear that only the successful management of cardiovascular manifestations of the Marfan syndrome is likely to increase individual life expectancy. Fortunately, both medical and surgical therapies have proven capable of achieving this goal (Svennson et al 1989; Smith et al 1994; Antmann 1994).

Considering the limitations of physical examination, to recognize cardiovascular abnormalities in Marfan syndrome, echocardiography, computed tomography (CT) scanning, or magnetic resonance imaging (MRI) play an important role in the diagnostic work-up. The most frequent cardiovascular manifestations include aortic root dilation and aortic dissection. Aortic dissection or rupture and aortic regurgitation most often lead to death. The ascending aorta, aortic valve, and mitral valve can be evaluated by the 2-dimensional echocardiography and color Doppler interrogation in the parasternal long-axis orientation, and measurements can be obtained with the help of M-mode echocardiography. There are, however, patients with severe pectus abnormalities in whom a technically acceptable surface echocardiogram is impossible, and even transesophageal echocardiography (TEE) may be inadequate. MRI is an excellent alternative for these patients, as well as for pregnant patients in whom echocardiography is sometimes difficult (Schaeter et al 1987).

\section{Aortic root involvement}

Aortic abnormalities are found in $60 \%$ to $90 \%$ of patients with Marfan syndrome (Brown et al 1975; Devereux and Roman 1999). The aortic root involvement is the classic feature with a greater prevalence in males than in females (Brown et al 1975). The sinuses of Valsalva are usually dilated at birth and were abnormal throughout life in proportion to body surface area with a variable rate of progression during adolescence (Gova et al 1990; Reed et al 1993). Echocardiographic criteria for aortic root dilation as proposed by Brown and colleagues (1990) include a) width index of the aorta $>22 \mathrm{~mm} / \mathrm{m}^{2}$; b) actual measurement of an aortic diameter
$>40 \mathrm{~mm}$; and c) left atrial to aortic diameter ratio $>0.7$. Aortic diameter should be measured at the sinuses of Valsalva and related to normal values based on age and body surface area (Roman et al 1989). Aortic dilatation may be limited to the sinus of Valsalva or may involve the proximal and mid ascending aorta and increases at a variable rate. Hwa and colleagues (1993) reported an increase in $42 \%$ of Marfan patients by $1.9 \mathrm{~mm}$ yearly. The severity of aortic dilatation is related to the degree of aortic dilatation and to the length of the dilated segment. Generalized aortic dilatation in patients with Marfan syndrome is a marker for increased risk of subsequent aortic complications (Roman et al 1993). Dilatation of the aorta is accompanied in $15 \%$ to $44 \%$ by aortic regurgitation (Roman et al 1993). A myxomatous aortic valve may also contribute to aortic regurgitation (Roberts and Honig 1985). Conventionally, regurgitation results from stretching of the commissures at the sino-tubular junction; therefore, at least a moderate degree of root dilation is necessary before a valvular leakage is present (Roberts and Honig 1985). For example, aortic regurgitation is uncommon in an adult with a maximum root dimension of 45 to $50 \mathrm{~mm}$, but it is always present when the dimension is $>60 \mathrm{~mm}$ (von Kodolitsch et al 1998a); cusp fenestrations or dissection can cause aortic regurgitation regardless of aortic dimension.

\section{Aortic dissection}

The prevalence of Marfan syndrome among patients with aortic dissection is unclear but recent data from the International Registry of Aortic Dissection (IRAD) reported that $5 \%$ of the 1049 patients had this disorder (Januzzi et al 2004) (Table 1). In other surveys the rate ranges between 3.2\% and 5.8\% (von Kodolitsch et al 2000; Mehta et al 2002). Aortic dissection generally occurs in the presence of an enlarged aortic root $(>40 \mathrm{~mm})$ and is associated with a family history of dissection. Aortic dilatation and dissection are mainly observed on the proximal part of the ascending aorta, just above the coronary ostia, which is submitted to maximal hemodynamic stress and is the richest in elastic fibers as well as in fibrillin which may contribute to the pathogenesis of aortic dissection. The association between increased aneurysm diameter and the risk for dissection or rupture is clearly established so that an aneurysm size $>6 \mathrm{~cm}$ cause a 4 -fold increase in the cumulative risk (Davies et al 2002). However, $20 \%$ of dissections occur in patients with a normal aortic root size $(<40 \mathrm{~mm})$. Less than $20 \%$ of acute dissections in patients with Marfan syndrome are type B lesions; these usually arise distal to the left subclavian artery in an often undilated descending thoracic aorta (Hagan et al 2000). Moreover 
Table I Characteristics of patients with and without Marfan syndrome in the International Registry of Aortic Dissection (IRAD) (Januzzi et al 2004)

\begin{tabular}{|c|c|c|c|}
\hline & $\begin{array}{l}\text { Marfan } \\
\text { syndrome }\end{array}$ & $\begin{array}{l}\text { Non-Marfan } \\
\text { syndrome }\end{array}$ & p-value \\
\hline Age (years) & $35 \pm 12$ & $64 \pm 13$ & $<0.001$ \\
\hline Systemic hypertension (\%) & 27 & 74 & $<0.001$ \\
\hline Prior aortic aneurysm (\%) & 33 & 13 & $<0.001$ \\
\hline Prior aortic dissection (\%) & 23 & 4 & $<0.001$ \\
\hline \multicolumn{4}{|l|}{ Prior cardia surgery due } \\
\hline to aortic dissection (\%) & 27 & 8 & $<0.001$ \\
\hline \multicolumn{4}{|l|}{ Prior aortic valve } \\
\hline replacement (\%) & 19 & 4 & $<0.001$ \\
\hline Sinus of Valsalva $(\mathrm{cm})$ & $5,05 \pm 1,75$ & $4,11 \pm 0,96$ & 0.006 \\
\hline Ascending aorta $(\mathrm{cm})$ & $5,29 \pm 1,75$ & $4,77 \pm 1,31$ & 0.09 \\
\hline Type A dissection (\%) & 76 & 62 & 0.04 \\
\hline Intramural hematoma & 2 & II & 0.03 \\
\hline
\end{tabular}

pregnancy in patients with Marfan syndrome is associated with an increased risk of aortic dissection, especially during the third trimester, birth and the first month post partum (Pyeritz 1981).

Type A dissection is the leading cause of death in Marfan syndrome, most frequently through retrograde extension into the pericardium with resulting lethal tamponade (Murdoch et al 1972). Acute dissection may be accompanied by all of the classic signs and symptoms, or it may be clinically silent. Some patients, however, feel that something is suddenly and definitely wrong and hurry to the emergency room where they are often misdiagnosed. Close inspection of the medical records of many such cases reveals that a life-threatening condition should have been suspected, either from the symptoms and signs or simply because the patient was known to have Marfan syndrome. The recommendations regarding timing of surgical repair have been determined, in part, by an appreciation of the risk of dissection. It has become clear recently that this risk is not the same for all aortas at a given diameter (Roberts and Honig 1985). A comparison between patients who sustained dissection, patients who underwent prophylactic repair of the aorta, and patients awaiting such surgery revealed that a family history of dissection is useful for stratification (Pyeritz 1991).

\section{Indication for surgery}

Aortic dissection and rupture are the leading causes of morbidity and mortality in Marfan syndrome, and prophylactic surgery is recommended to prevent this complication. The indication for prophylactic aortic surgery is been predicated on aortic size and recommended when the diameter reaches $5.0 \mathrm{~cm}$ (Smith et al 1994; Davies et al 2002) or the diameter reaches twice of the adjacent segments (Svennson et al 1989; Smith et al 1994). Factors that promptly wants the recommendation for surgery when the aorta is $<5.0 \mathrm{~cm}$ include rapidly growth of the aortic diameter (5\%/ year) (Antmann 1994), a family history of premature aortic dissection and the presence of greater than mild aortic regurgitation. (Table 2).

\section{Indication for endovascular intervention after previous aortic surgery}

Even after successful aortic root replacement, however, the dissected descending aorta remains a source of late complications in Marfan syndrome (von Kodolitsch et al 1994). The role of percutaneous stent-grafting for treatment of aortic pathologies in Marfan patients after aortic surgery is not established yet. In very small number of treated patients several groups could show the feasibility of stent-graft placement with good short-term results (Nienaber et al 1999; Ince et al 2003; Wheatley et al 2006; Fattori et al 2006). The aim is to avoid an enlargement of the aorta or of the false lumen by sealing the proximal entry tear with a customized stentgraft. Because of being a disease of the entire aorta, this procedure is just a therapeutic option to avoid a repeated aortic surgery. The reason for stent-graft placement against repeat aortic surgery in first line is the mortality rate of $31 \%$ for repeated aortic surgery in Marfan patients (Carrel et al 1993; Gott et al 1999, 2002).

\section{Technique of endovascular stent-graft placement}

Based on diagnosed measurements obtained during angiography, transesophageal echography, or tomographic spiral CT or MRI, customized stent-grafts can be used to both scaffold up to $20 \mathrm{~cm}$ of dissected or dilatated aorta and cover major tears. The procedure is best performed in a hybrid laboratory with catheterization and imaging capabilities including digital angiography under general anesthesia and ventilation. The femoral artery is the most popular access-site and can usually accommodate a $24 \mathrm{~F}$ stent-graft system. The procedure will begin by injecting 5000 units of heparin. The femoral or distal iliac artery is surgically exposed. Using the Seldinger technique, a $260 \mathrm{~cm}, 0.89 \mathrm{~mm}(0.035$ inch) stiff wire is placed over a pigtail catheter navigated with a soft wire in the true lumen under both fluoroscopic and transesophageal ultrasound guidance. In complex cases with multiple reentries in the abdominal aorta, the embracement-technique with the use of 2 pig-tail catheters is useful. A pig-tail catheter, which 
Table 2 Flow chart for managment of Marfan patients with aortic disease

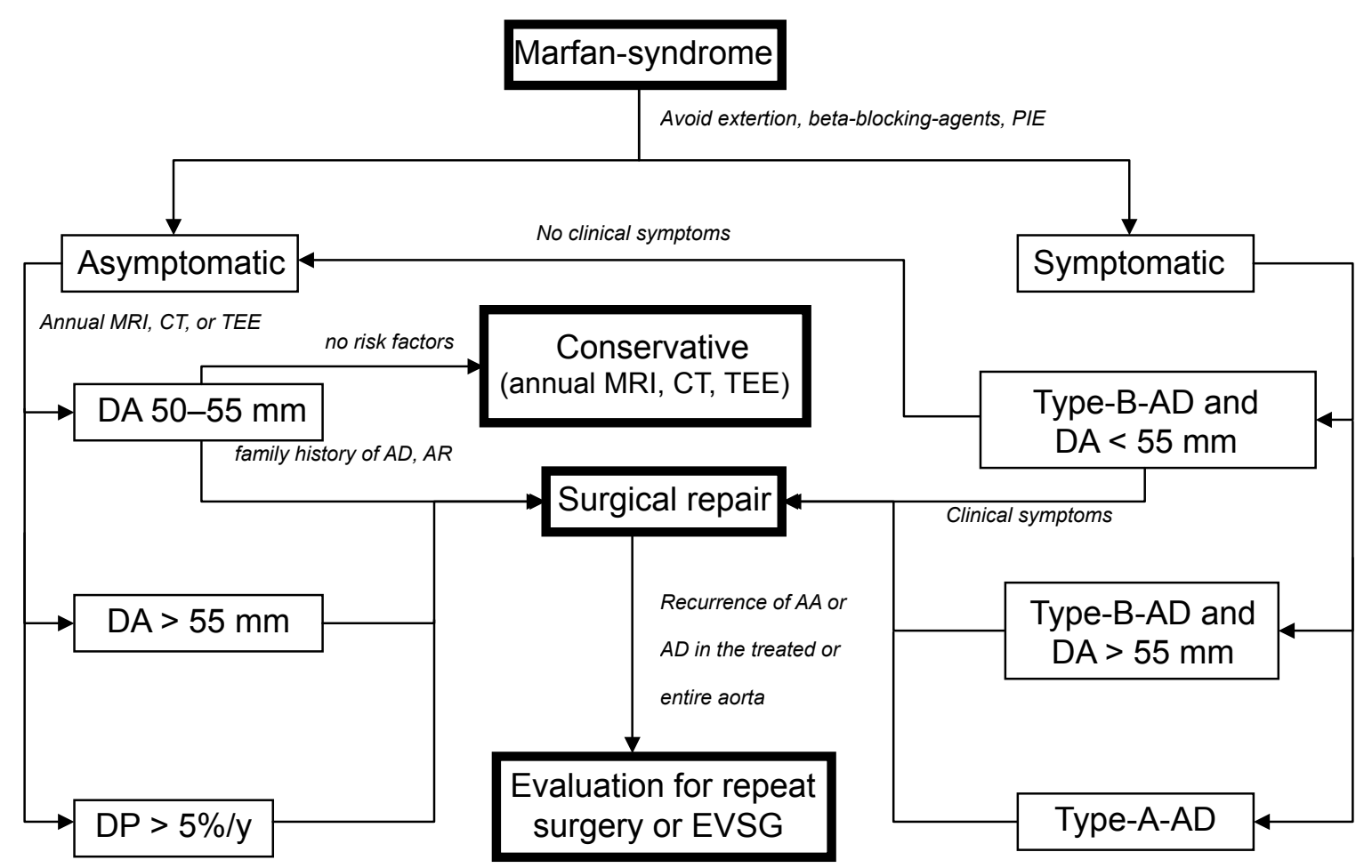

Abbreviations: PIE, prophylaxix of infective endocarditis;AD, aortic dissection;AR, aortic regurgitation; DP, diameter progression; EVSG, endovascular stent graft; AA, aortic aneurysm; DA, diameter of the aorta.

has been installed in the true aortic lumen via the left brachial artery, picks up the femoral pig-tail catheter in the true lumen of the abdominal aorta and pulls it up into the aortic arch. This procedure ensures definite positioning of the stiff guide wire in the true lumen, which is essential for correct deployment of the stent-graft. Carefully advanced over the stiff wire, the launching of the stent-graft is performed with systolic blood pressure lowered to $50-60 \mathrm{mmHg}$ by infusion sodium nitroprusside or by rapid right ventricular pacing to avoid misplacement. After deployment short inflation of a latex balloon can improve apposition of the stent struts to the aortic wall, but only if proximal sealing of thoracic communications is incomplete. Both Doppler-ultrasound and contrast fluoroscopy are instrumental for documenting the immediate result or initiating adjunctive maneuvers. After removing the sheath and guidewire the access sites can be closed in standard fashions.

\section{Own experiences}

There are only few data concerning stent-grafts to avoid repeat surgery for complicated persistent distal dissection after previous root replacement. In our institution, endovascular reconstruction of a dissected Marfan aorta was subsequently attempted in seven consecutive cases with previous root replacement and in one case with isolated type B dissection. Transluminal placement of customized stentgrafts was technically successful in 8 patients with Marfan syndrome with no 30 day or 1 year intervention-related mortality and without any signs of neurological complications (Figure 1). The follow-up ranges from 12 to 92 months (mean $63 \pm 19$ ). Mean stent-graft length was $151 \pm 23 \mathrm{~mm}$ (range 90-180). Stent-graft procedures lasted a mean $132 \pm$ 34 minutes (range 97-236). False lumen thrombosis was seen in 6 of 8 patients. Complete abolition of the dissection and reconstruction of the entire dissected aorta was documented in 4 patients, and conversion to elective surgical repair in 3 patients $(22,43$, and 80 months after stent-graft implantation) due to enlargement of the false lumen. One patient died suddenly 12 months after endovascular repair.

\section{Results from the literature}

In the survey performed by Baril and colleagues (2006) 11 of 1073 patients treated with endovascular stent-graft had an arteriopathy, 6 had Marfan syndrome, 3 had Takayasu's Arteritis, and 2 had a giant cell arteritis. Eight of the 11 patients had undergone previous aortic surgery. Technical success of 

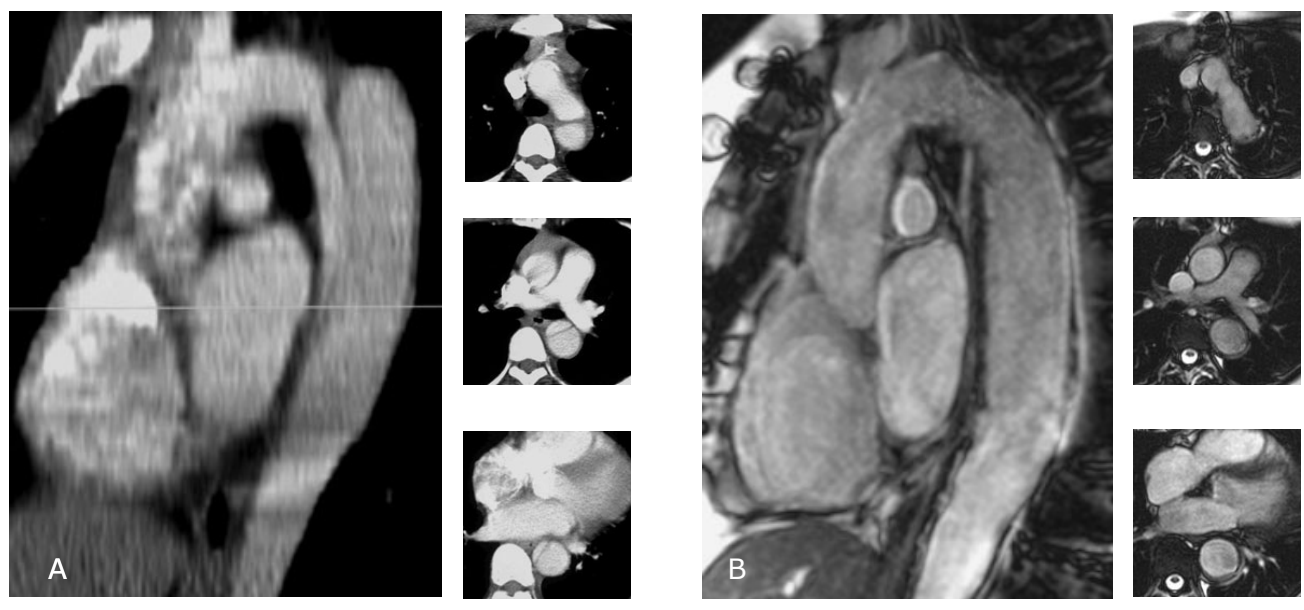

Figure I A. Sagittal view of a contrast enhanced computed tomography scan showing a native type B aortic dissection in a young Marfan syndrome patient; the 3 pictograms in axial view identify a small true lumen and a larger false. B. Gd-enhanced MR tomogram in sagittal orientation; Follow-up study one year after endovascular stent-graft placement showing no resident false lumen and reconstruction of the dissected aorta as confirmed on axial pictograms.

the endovascular stent-graft placement was achieved in $92 \%$. Early complications like wound infection and postoperative myocardial infarction was seen in $25 \%$. There were no perioperative mortalities or immediate conversion to open surgery (Baril et al 2006). Elective conversion to open surgery was performed in 3 of 6 patient in the follow-up (28 and 52 month after EVSG) due to progression of the aortic disease in the entire aorta $(n=2)$ and due to rupture of the intercostal patch $(n=1)$. Similar satisfactory results with asymtomatic subjects and lacking signs for a dilatation in the treated aorta were reported in other case reports (Umana et al 2002; Fleck et al 2003; Dong et al 2005; Gaxotte et al 2006). Botta and colleagues (2006) treated succesfully a patient with unusual rapid evolution of type $\mathrm{B}$ aortic dissection following heart transplantation, which had an incidence of $40 \%$ for thoracic aortic dissection. The mortality rates of endovascular stentgrafts for patients with acute aortic syndromes range from $0 \%$ to $16 \%$ while the same patients treated surgically would have a risk in the range of $40 \%$ or perhaps even exceeding up to $70 \%$ if treated medically (Fann et al 1994).

Roux and colleagues (2002) treated a fistula at the distal anastomisis after Bentall operation with endovascular stent graft with complete occlusion of the false aneurysm documented in the control comuted tomography in a 25-year-old Marfan patient. Another 42-year-old Marfan patient with type B dissection distal from the left subclavian artery up to the right iliac artery with no lower limb pulses and a poor perfusion of the left kidney was treated by Zaman and colleagues (2002) showing complete healing in the axial imaging performed one year later with no symptoms of lower limb paralysis nor left arm claudication (Table 3).

\section{Discussion}

Marfan syndrome is a generalized polymorphic inherited disease of connective tissue with large interfamilial and intrafamilial variability, complete penetrance, and autosomal dominant transmission. It is relatively common, with an incidence of 1 per 10.000 with no difference according to gender, race, or ethnicity and is clinical characterized by abnormalities of the skeletal, ocular, and cardiovascular system (Pyeritz 1979).

Before delicate aortic surgery became available on a broader scale, the majority of patients with Marfan syndrome died prematurely of aortic rupture, often in their early adulthood (Gott et al 2002). In a survey performed by Murdoch and colleagues (1972) 50\% of men affected by Marfan syndrome were dead by the age of 40 years. The success of current medical and surgical treatment of aortic disease in Marfan syndrome patients has substantially improved the average life expectancy, extending it up to 70 years (Finkbohner et al 1995; Silvermann et al 1995). Umana and colleagues (2002) reported a trend to lower mortality risk: from $57 \%$ between 1963 and 1969, to 27\% between 1990 to 1999 for surgical patients. Introduction of both Bentall procedure (Bentall and DeBono 1968), composite graft conduits, and root reconstruction eventually changed the bleak outlook for Marfan syndrome patients with aneurysm of the ascending aorta with improvement of the 10 year survival rate in prophylactic 


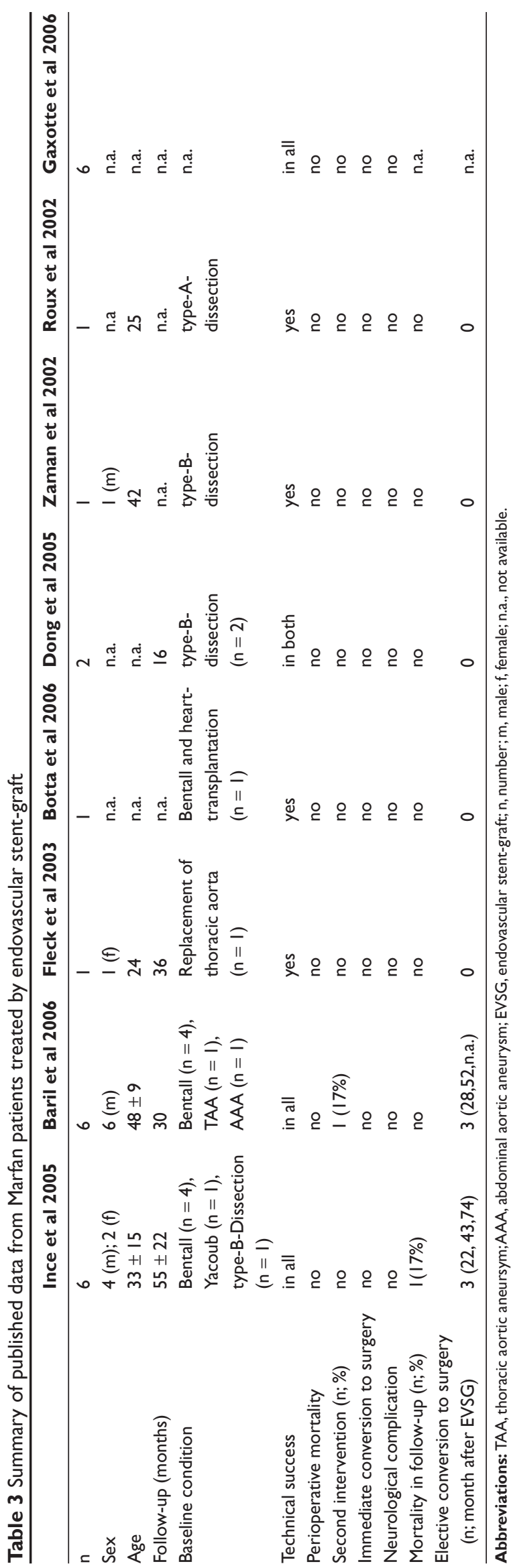

aortic root replacement up to $97 \%$ compared with $34 \%$ in patients who did not undergo surgical intervention (Groenik et al 1999). A survey in 10 major Marfan centers reported a 30 -day mortality rate of $1.5 \%$ for patients undergoing elective repair of aortic root aneurysms; and $11.7 \%$ among patients requiring emergent surgery (Gott et al 1999). Even after successful aortic root replacement, however, the dissected descending aorta remains a source of late complications in Marfan syndrome (von Kodolitsch et al 1999).

In contrast to excellent surgical results of elective root replacement, both early and long-term results of repeat surgery for the descending aorta, which is required subsequently in $10 \%$ to $27 \%$ (von Kodolitsch et al 1998b), remain poor and had a mortality rate up to $31 \%$ (Silvermann et al 1995; Gott et al 1999, 2002; DeOliveira et al 2003). In the report of DeOliveira and colleagues (2003) including 4 Marfan patients with previous aortic root surgery requiring replacement of both the thoracic and abdominal aorta for expansion or imminent rupture of the false lumen 1 patient died, a second became paraplegic, and only 2 fared well. In a recent study by Alexiou and colleagues (2001) 3 of 7 patients with Marfan syndrome and late postoperative aortic complications underwent resurgery of the descending aorta after previous aortic root replacement with a $33 \%$ mortality. A larger survey reported 63 of 653 Marfan syndrome patients with previous aortic root replacement to require late aortic surgery for progressive disease; only 46 patients were alive at the time of last follow-up (Dong et al 2005). More than half of these second interventions take place without direct anatomical relation with the preoperated aortic segment. In $40 \%$ of patients, local complications of the preoperated aorta in the area of the aorta ascendens or the aortic arch lead to an individualized second intervention (von Kodolitsch et al 1998b).

The postoperative mortality rate is determined by late aortic dissection in 33\% and progressive heart failure in $35 \%$ of the Marfan patients with previously aortic surgery. Five and 15 year survival rate were $71 \%$ to $88 \%$ and $71 \%$ respectively (von Kodolitsch et al 1998b).

In contrast to the increased risk of repeat aortic surgery endovascular stent-graft repair could be a feasible alternative to open surgery in selected cases. To date there are only limited experiences with stent-grafts in Marfan patients (Table 3).

This limited data demonstrate not only technical feasibility, but also some therapeutic potential of endovascular stentgraft treatment in Marfan syndrome with distal dissection after complex aortic root repair or acute aortic syndrome. The technical execution of endovascular stent-graft deployment 
was safe, since peri- and post-interventional outcomes were favorable. Preservation of the integrity of the aorta, rather than surgical resection, has previously proven to avoid neurological events and interference with spinal artery supply (Rapezzi et al 2001; Ince et al 2003). None of our patients had neurological or vascular events, although the risk of paraplegia with elective surgery of the descending aorta is estimated at $8 \%$; such risk figures pertain to centers with special experience in aortic surgery, and to patients without any previous surgical repair of the aorta (Eleftriades 2002). Although the endovascular strategy was employed in relatively few patients and observational in nature, it revealed a feasible and relatively safe nonsurgical alternative to treat descending aortic dissection in Marfan patients after aortic surgery. Regardless of feasibility, however, conversion to surgery after stent-graft placement underlines that endovascular stent-grafting should be considered a bridging rather than curative procedure, which was also confirmed by the data of Baril and colleagues (2006). They could demonstrate that 2 of 6 initially successful treated patients had to be converted to surgery due to abnormalities in the entire aorta. Furthermore, with death of one patient (12 month after stent-graft implantation) who suffered from complex aortic pathology both close surveillance and repeat imaging of the aorta appear mandatory to detect silent postinterventional complications eventually requiring surgical repair.

Although conceptually promising - considering sobering results of surgical repair (Svennson et al 2004) - adjunctive management by stent-graft placement in distally extending dissection lacks the support of long-term follow-up data. Nevertheless, over several years of follow-up after stent-graft placement for the treatment of both thoracic and abdominal aneurysms, late adverse effects were infrequent and may justify "bridging" stent-grafts even in relatively young patients with Marfan syndrome after aortic root surgery (Nienaber et al 1999a, 1999b; Ince et al 2003, 2005; Svennson et al 2004) in the attempt to avoid the risks of (emergent) repeat surgery.

In summary, due to the lack of long-term follow-up experience and small number of cases published, endovascular stent-graft treatment may emerge in the future as a feasible therapeutic option for Marfan patients with late distal complications following aortic surgery, but clear evidence is still missing.

\section{References}

Alexiou C, Langley SM, Charlesworth P, et al. 2001. Aortic root replacement in patients with Marfan's syndrome: the Southampton experience. Ann Thorac Surg, 72:1502-8.
Antman EM. 1994. Current diagnosis and prescription for Marfan syndrome: When to operate. J Card Surg, 9:174-6.

Baril DT, Carroccio A, Palchik E, et al. 2006. Endovascular treatment of complicated aortic aneurysms in patients with undelying arteriopathies. Ann Vasc Surg, 20:464-71.

Bentall HH, DeBono A. 1968. A technique for complete replacement of the ascending aorta. Thorax, 23:338-9.

Botta L, Russo V, Grigioni F, et al. 2006. Unusual rapid evolution of type $\mathrm{B}$ aortic dissection in a marfan patient following heart transplantation: successful endovascular treatment. Eur J Vasc Endovasc Surg, 32:358-60.

Brown OR, DeMots H, Kloster FE, et al. 1975. Aortic root dilatation and mitral valve prolapse in Marfan syndrome: An Echocardiographic study. Circulation, 52:651-7.

Carrel T, Pasic M, Jenni R, et al. 1993. Reoperations after operation on the thoracic aorta: etiology, surgical techniques and prevention. Ann Thorac Surg, 56:259-68.

Davies RR, Goldstein LJ, Coady MA, et al. 2002. Yearly rupture or dissection rates for thoracic aortic aneurysms: simple prediction based on size. Ann Thorac Surg, 73:17-27.

De Oliveira NC, David TE, Ivanov J, et al. 2003. Results of surgery for aortic root aneurysm in patients with Marfan syndrome. $J$ Thorac Cardiovasc Surg, 125:789-96.

Devereux RB, Roman MJ. 1999. Aortic disease in Marfan's syndrome. N Engl J Med, 340:1358-9.

Dong XU S, Zhong Li Z, Huang FJ, et al. 2005. Treating aortic dissection and penetraiting aortic ulcer with stent graft: thirty cases. Ann Thorac Surg, 80:864-8.

Elefteriades JA. 2002. Natural history of thoracic aortic aneurysms: indications for surgery, and surgical versus nonsurgical risks. Ann Thorac Surg, 74:S1877-80.

Fann JI, Smith JA, Miller DC, et al. 1995. Surgical management of aortic dissection during a 30-year period. Circulation, 92(9 Suppl):113-21.

Fattori R, Nienaber CA, Descovich B, et al. 1999. Importance of dural ectasia in phenotypic assessment of Marfan's syndrome. Lancet, 354:910-13.

Fattori R, Nienaber CA, Rousseau H, et al. 2006. Thoracic Retrospective Registry. Results of endovascular repair of the thoracic aorta with the Talent Thoracic stent graft: the Talent Thoracic Retrospective Registry. J Thorac Cardiovasc Surg, 132:332-9.

Finkbohner R, Johnston D, Crawford ES, et al. 1995. Marfan syndrome. Long-term survival and complications after aneurysm repair. Circulation, 91:728-33.

Fleck TM, Hutschala D, Tschernich H, et al. 2003. Stent graft placement of the thoracoabdominal aorta in a patient with Marfan syndrome. J Thorac Cardiovasc Surg, 125:1541-3.

Gaxotte V, Thony F, Rousseeau H, et al. 2006. Midterm results of aortic diameter outcomes after thoracic stent-graft implantation for aortic dissection: a multicenter study. J Endovasc Ther, 13:127-38.

Gott VL, Greene PS, Alejo DE, et al. 1999. Replacement of the aortic root in patients with Marfan's syndrome. $N$ Engl J Med, 340:1307-13.

Gott VL, Cameron DE, Alejo DE, et al. 2002. Aortic root replacement in 271 Marfan patients: a 24-year experience. Ann Thorac Surg, 73:438-43.

Gova T, Sanders SP, Diogenes MS, et al. 1990. Two-dimensional and Doppler echocardiography and pathologic characteristics of the infantile Marfan syndrome. Am J Cardiol, 65:1230-7.

Groenik M, Lohuis TA, Tijssen JG, et al. 1999. Survival and complication free survival in Marfans syndrome : implications on current guidelines. Heart, 82:499-504.

Hagan PG, Nienaber CA, Isselbacher EM, et al. 2000. The International Registry of Acute Aortic Dissection (IRAD): new insights into an old disease. JAMA, 283:897-903.

Hwa J, Richards JG, Huang H, et al. 1993. The natural history of aortic dilatation in Maran syndrome. Med J Aus, 158:558-62.

Ince H, Petzsch M, Rehders T, et al. 2003. Percutaneous endovascular repair of aneurysm after previous coarctation surgery. Circulation, 108:2967-70. 
Ince H, Rehders TC, Petzsch M, et al. 2005. Stent-grafts in patients with marfan syndrome. J Endovasc Ther, 12:82-8.

Januzzi JL, Marayati F, Mehta RH, et al. 2004. Comparison of aortic dissection in patients with and without Marfan's syndrome (results from the International Registry of Aortic Dissection). Am J Cardiol, 94:400-2.

Mehta RH, O'Gara PT, Bossone E, et al. 2002. Acute type A aortic dissection in the elderly: clinical characteristics, management and outcomes in the current era. J Am Coll Cardiol, 40:685-92.

Murdoch JL, Walker BA, Halpern BL, et al. 1972. Life expectancy and cause of death in Marfan syndromes. N Engl J Med, 286:804-8.

Nienaber CA, von Kodolitsch Y. 1999a. Therapeutic managment of patients with Marfan syndrome: focus on cardiovascular involvment. Cardiol Rev, 7:332-41.

Nienaber CA, Fattori R, Lund G, et al. 1999b. Nonsurgical reconstruction of thoracic aortic dissection by stent-graft placement. $N$ Engl J Med, 340:1539-45.

Pyeritz RE, McKusick VA. 1979. The Marfan syndrome: diagnosis and management. N Engl J Med, 300:772-7.

Pyeritz RE. 1981. Maternal and fetal complications of pregnancy in the Marfan syndrome. Am J Med, 71:784-90.

Pyeritz RE. 1991. Predictors of dissection of the ascending aorta in Marfan syndrome. Circulation, 84:351-8.

Rapezzi C, Rocchi G, Fattori R, et al. 2001. Usefulness of transesophageal echocardiographic monitorino to improve the outcome of stent-graft treatment of thoracic aortic aneurysms. Am J Cardiol, 87:315-19.

Reed CM, Richley PA, Pullam DA, et al. 1993. Aortic dimensions in tall men and women. Am J Cardiol, 71:608-11.

Roberts WC, Honig HS. 1985. The spectrum of cardiovascular disease in the Marfan syndrome: A clinico-morphologic study of 18 necropsy patients and comparison to 151 previously reported necropsy patients. Am Heart J, 104:115-35.

Roman MJ, Devereux RB, Kramer-Fox R, et al. 1989. Two-dimensional echocardiographic aortic root dimensions in normal children and adults. Am J Cardiol, 64:507-12.

Roman MJ, Rosen SE, Kramer-Fox R, et al. 1993. Prognostic significance of the pattern of aortic root dilatation in the Marfan syndrome. $J$ Am Coll Cardiol, 22:1470-6.
Roux D, Brouchet L, Rousseau H, et al. 2002. Treatment of a fistula at the distal anastomosis after Bentall operation with endoluminal covered stent. Ann Thorac Surg, 74:2189-90.

Schaeter P, Peshok RM, Malloy CR, et al. 1987. Nuclear magnetic resonance imaging in Marfan's syndrome. J Am Coll Cardiol, 9:70-7.

Silverman DI, Burton KJ, Gray J, et al. 1995. Life expectancy in the Marfan syndrome. Am J Cardiol, 75:157-60.

Smith JA, Fann JI, Miller C, et al. 1994. Surgical management of aortic dissection in patients with Marfan syndrome. Circulation, 90:235-42.

Svennson LG, Crawford S, Coselli JS, et al. 1989. Impact of cardiovascular operation on survival in the Marfan patient. Circulation, 80:233-42.

Svennson LG, Kim KH, Blackstone EH, et al 2004. Elephant trunk procedure: newer indications and uses. Ann Thorac Surg, 78:109-16.

Umana JP, Miller DC, Mitchell RS. 2002. What is the best treatment for patients with acute type B aortic dissection- medical, surgical or endovascular stent-grafting? Ann Thorac Surg, 74:1840-3.

Van Karnebeek CD, Naeff MS, Mulder BJ, et al. 2001. Natural history of cardiovascular manifestation in Marfan syndrome. Arch Dis Child, 84:129-37.

von Kodolitsch Y, Reghunath M, Nienaber CA. 1998a. Marfan syndrome: prevalence and natural cource of cardiovascular manifestations. Z Kardio, 87:150-60.

von Kodolitsch Y, Raghunath M, Karck M, et al. 1998b. Marfan syndrome: therapy of cardiovascular manifestations. Z Kardiol, 87:173-84.

von Kodolitsch Y, Simic O, Schwartz A, et al. 1999. Predictors of proximal aortic dissection at the time of aortic valve replacement. Circulation, 100:II287-94.

von Kodolitsch Y, Schwartz AG, Nienaber CA. 2000. Clinical prediction of acute aortic dissection. Arch Intern Med, 160:2977-82.

Wheatley GH 3rd, Gurbuz AT, Rodriguez-Lopez JA, et al. 2006. Midterm outcome in 158 consecutive Gore TAG thoracic endoprostheses: single center experience. Ann Thorac Surg, 81:1570-7.

Zaman MJS, Carre V, Parvin S, et al. 2002. Endovascular stent repair for a dissecting thoracoabdominal aneurysm in feasible in the setting of a district general hospital: a multidisciplinary approach. Heart, 88:E4. 